\title{
Increased Expression of Estrogen Receptor $\alpha-36$ by Breast Cancer Oncogene IKK $\varepsilon$ Promotes Growth of ER-Negative Breast Cancer Cells
}

\author{
Qihong Li ${ }^{a, b, c, e}$ Haiyan Sun ${ }^{c, e}$ Jingcai Zou ${ }^{c}$ Cheng Ge ${ }^{c}$ Kaitao Yuc Yuan Cao ${ }^{d}$ \\ Quan Hong
}

aSchool of Stomatology, Fourth Military Medical University, Xi'an, China; ${ }^{b}$ Department of Nephrology, State Key Laboratory of Kidney Disease, Chinese PLA General Hospital, 2011DAV00088, Beijing, PR China; 'Affiliated hospital of Academy of Military Medical Sciences, Beijing, China; ${ }^{d}$ Department of Laboratory Medicine, Jinan Military General Hospital, Jinan, Shandong, China; ${ }^{\mathrm{Q}}$ Qihong Li and Haiyan Sun contributed equally to this work and should be regarded as the co-first authors

\section{Key Words}

IKK $\bullet$ ER- $\alpha 36 \bullet$ ER-negative breast cancer

\begin{abstract}
Background/Aims: The expression of estrogen receptor- $\alpha(E R \alpha)$ is one of the most important diagnostic and prognostic factors of breast cancer. Recently, ER $\alpha-36$ has been identified as a novel variant of ER- $\alpha$. ER $\alpha-36$ lacks intrinsic transcription activity and mainly mediates nongenomic estrogen signaling. The noncanonical IKK family member IKKE is essential for regulating antiviral signaling pathways and is recently discovered as a breast cancer oncogene. IKK $\varepsilon$ interacts with and phosphorylates ER $\alpha$ on serine 167, induces ER $\alpha$ transactivation activity and enhances ER $\alpha$ binding to DNA in ER-positive breast cancer cells. However, the correlation between IKK $\varepsilon$ and the ER $\alpha-36$ signaling pathway in ER-negative breast cancer cells remains unclear. Methods and Results: In this study, we show that IKKE interacts with ER $\alpha-36$ and increases its expression in breast cancer cells. As shown by western blot assays, the upregulation of ER $\alpha-36$ by IKK $\varepsilon$ was significant. In MDA-MB-231 cells which are ER-negative, IKK $\varepsilon$ was able to increase the expression of ER $\alpha-36$ in a dose-dependent manner, and the RNA interference assay indicated the correlation between IKK $\varepsilon$ and ER $\alpha-36$ expression. Moreover, IKK $\varepsilon$ enhanced the growth of MDA-MB-231 and MDA-MB-436 cells. Conclusions: These results suggest that IKK $\varepsilon$ increases $E R \alpha-36$ expression and is involved in $E R \alpha-36$ mediated non-genomic estrogen signaling.
\end{abstract}


Li et al.: IKKE Increase Expression of ER $\alpha-36$ in ER-Negative Breast Cancer Cells

\section{Introduction}

Breast cancer is the most common cancer among women, the ER signaling pathway plays a pivotal role in the development of different types of breast cancer [1,2]. Two types of ERs have been identified, $E R \alpha$ and $E R \beta[3,4]$. There are 3 types of $E R \alpha$ isoforms identified: 66-KD, 46-KD and 36-KD [5]. Tumors expressed ER $\alpha$-66 were considered as ER $\alpha$-positive [6]. Previous studies indicated that approximately $70 \%$ of these tumors express estrogen receptor $\alpha$ [7]. Patients with $\mathrm{ER} \alpha$-positive tumors are associated with a well differentiated phenotype and have a better prognosis; ER-negative tumors had a shorter disease-free interval and overall survival than patients with ER-positive tumors [8]. Although significant progress has been made in the development of endocrine therapies that target estrogen or ER for ER-positive tumors, there is no effective therapy for the $30 \%$ of breast cancers that are ER negative $[9,10]$. Recently, a $36-\mathrm{kDa}$ variant of ER $\alpha-66$, named ER-a36 has been identified, it is mainly expressed in the cytoplasm and plasma membrane and has minimal or no nuclear expression in breast cancer cells [11-13]. ER $\alpha-36$ was expressed in ER-negative tumor samples and ER-negative breast cancer cell lines [14]. Some studies have suggested that ER $\alpha-36$ is involved in nongenomic estrogen signaling, and ER $\alpha-36$ promotes cell proliferation via the MAPK/ERK pathway in ER-negative breast cancers $[13,14]$.

IKKe is one of noncanonical IKK family member that plays a critical role in the regulation of interferon signaling pathways [15-17]. When IKKE was activated, interferon regulatory factors 3 and 7 (IRF3 and IRF7) were phosphorylated, allowing their nuclear translocation and the transcriptional upregulation of genes involved in the type I interferon response. IKK $\varepsilon$ also phosphorylates STAT1 following activation by IFNb [18]. IKKe had been identified IKKe as a breast cancer oncogene amplified and overexpressed in over $30 \%$ of breast carcinomas and breast cancer cell lines [19]. Recently, it has also been demonstrated that IKKe phosphorylates Ser-167 of $\mathrm{ER} \alpha$, and induction of $\mathrm{ER} \alpha$ transactivation contributes to tamoxifen resistance in breast cancer [20].

In this study, we show for the first time that IKKe increases the expression of ER $\alpha$-36 in MDAMB-231 and MDA-MB-436 breast cancer cell lines. We further show that IKKe interacts with ER $\alpha$ 36. The results from our study also show that IKKe is involved in ER $\alpha$-negative breast cancer cell growth through regulation of ER $\alpha-36$ mediated mitogenic estrogen signaling, identifying a novel mechanism by which IKKe are constitutively activated in ER $\alpha$-negative breast cancer cells.

\section{Materials and Methods}

\section{Chemicals and antibodies}

The 17 $\beta$-estradiol $\left(\mathrm{E}_{2} \beta\right)$ was obtained from Sigma. The IKKe(I-4907), HA(H-6908), Flag(F-1804), $\beta$-actin(A-1978) antibodies were obtained from Sigma. The ER $\alpha$-36 antibody (CY1109) was obtained from Cell Applications. Cyclin D1(H-295), c-Myc(9E10) were obtained from Santa Cruz Biotechnology. IKKe (sc39056) siRNA was obtained from Santa Cruz Biotechnology.

\section{Cell lines, treatment and growth assay}

MDA-MB-231, MDA-MB-436 cells and human embryonic kidney cell line (HEK293) were obtained from the American Type Culture Collection (ATCC). All cells were maintained in Dulbecco's modied Eagle's medium and $10 \%$ fetal calf serum at $37^{\circ} \mathrm{C}$ in a $5 \% \mathrm{CO}_{2}$ incubator. For $\mathrm{E}_{2} \beta$ treatment, cells were maintained in phenolred-free media with $2.5 \%$ charcoal-stripped fetal calf serum (HyClone, Logan, UT, USA) for 3 days and then in serum-free medium for $24 \mathrm{~h}$ before experimentation.

To cell growth assays, cells were treated with indicated concentrations of $\mathrm{E}_{2} \beta$ or vehicle (ethanol) as a control. The cells were seeded at $1 \times 10^{4}$ cells per dish in $60 \mathrm{~mm}$ dishes and the cell numbers were determined using the ADAM automatic cell counter (Invitrogen, USA) after 12 days. Five dishes were used for each treatment and experiments were repeated more than three times. 
siRNA transfection

MDA-MB-231 and MDA-MB-436 cells were seeded at $2 \times 10^{5}$ cells/dish in $60 \mathrm{~mm}$ culture dishes $24 \mathrm{~h}$ before transfection. IKKe or control siRNA weighing $1 \mathrm{mg}$ was mixed with siRNA transfetion medium and siRNA transfection reagent (Santa Cruz Biotechnology) and incubated for $30 \mathrm{~min}$ at room temperature before added into cultured cells. The efficiency of siRNA knock-down was assessed with western blot analysis.

DNA Transfection and Luciferase Assays

For transient transfection assays, cells were seeded in six-well dishes and grown to 60-70\% confluence in phenol-red-free medium plus $2.5 \%$ steroid-free FCS. Cells were washed and transiently transfected with a total of 5 ug of plasmid with the FuGene6 reagent (Roche Molecular Biochemicals). The luciferase assays were performed by using the Luciferase Assay kit from Promega according to the manufacturer's recommendations. The Gal4 L-ELK plasmid was purchased from Stratagene. At $48 \mathrm{~h}$ after transfection, cell extracts were prepared and luciferase activities were determined and normalized using the Dual- Luciferase Assay System (Promega).

\section{Immunoprecipitation and immunoblot analysis}

For immunoprecipitation assays, cells were washed twice with ice-cold phosphate buffered saline and lysed with the lysis buffer (150mM NaCl, 20mM Tris- $\mathrm{HCl}, \mathrm{pH} 7.4,0.1 \% \mathrm{NP}-40)$ supplemented with protease and phosphatase inhibitors (Roche). Cell lysates were then incubated with indicated primary antibodies or pre-immune serum and immunoprecipitated with protein A/G plus agarose. The precipitates were then washed, separated on SDS-polyacrylamide gel electrophoresis and analyzed with western blot analysis.

For Western blot analyses, cells were disrupted with RIPA buffer, and the cell lysates were boiled in a gel-loading buffer and separated by SDS-PAGE in 10\% gels. After PAGE, the proteins were transferred to a poly vinylidene difluoride membrane (Millipore), and visualized with the appropriate species-specific peroxidase-conjugated secondary Abs (Santa Cruz Biotechnology) and enhanced chemiluminescence (ECL) reagents (Amersham Pharmacia).

\section{Immunohistochemistry}

Tumor tissues were collected from 25 cases of patients with ER-negative breast carcinomas with informed consent in Jinan Military General Hospital (Jinan, China). The design of the study was approved by the Hospital Ethical Committee. Immunohistochemistry (IHC) was carried out based on the method described before. Briefly, antigen retrieval was performed using $10 \mathrm{mM}$ sodium citrate buffer ( $\mathrm{pH} 6.0$ ) in a $95^{\circ} \mathrm{C}$ water bath for 15 minutes. Then primary antibody was used overnight at $4{ }^{\circ} \mathrm{C}$ in a humidified chamber, followed by secondary antibody.

\section{Statistical analysis}

Statistical analysis was carried out using the Statistical Package for Social Sciences 13.0 (SPSS). Data are presented as the means \pm SEM. Statistical significance was determined by a one-way analysis of variance or the t-test. P-values $<0.05$ were considered to indicate statistically significant differences.

\section{Results}

IKKE interacts with ER $\alpha-36$

Because IKK $\varepsilon$ interacts with the ER $\alpha-66$, which has conserved domains similar to those of ER- $\alpha$, we next examined whether ER $\alpha-36$ interacts with IKKe. The coimmunoprecipitation was performed in HEK-293T cells, which had been transfected with HA-ER $\alpha-36$ and Flag-IKKe. ER $\alpha$ 36 was detected in flag-IKKe immunoprecipitates (Fig. 1A). Furthermore, endogenous ER $\alpha-36$ and IKKe were able to form a complex in MDA-MB-231 cells (Fig. 1, B and C), which express $\mathrm{ER} \alpha-36$ as well as high levels of IKKe .These findings indicate that ER $\alpha-36$ interacts with IKKe. To further explore the molecular basis of the interaction between IKK $\varepsilon$ and ER $\alpha-36$, the regions of IKK $\varepsilon$ were defined. Results of co-immunoprecipitation experiment showed that the kinase domain (1-290 amino acids) of IKKe were indispensable for their interaction (Fig. 1D). In order to obtain evidence of direct IKKe phosphorylation of ER $\alpha-36$, recombinant GST-ER $\alpha-36$ was incuba- 
Fig. 1. IKKe and interacts with $\mathrm{ER} \alpha-36$. (A) IKKe interacts with $\mathrm{ER} \alpha-$ 36. HEK-293T cells were transfected with Flag-IKKe and HA- ER $\alpha-36$. After a 24-h incubation, cells were lysed and immunoprecipitated with antiFlag antibody. The immunoprecipitates were immunoblotted with antiHA antibody and anti-Flag antibody. (B and C) endogenous ER $\alpha-36$ binds to IKKe. MDA-MB-231 cells, expressing ER $\alpha-36$ and IKKe, were immunoprecipitated with anti-ER $\alpha-36$ and detected with anti-IKK $\varepsilon$ antibody (B) and vice versa (C). IgG was used as a control for coimmunoprecipitation. (D) $293 \mathrm{~T}$ cells were co-transfected with the indicated plasmids, and anti-Flag immunoprecipitates were analyzed by immunoblotting with anti-HA or anti-Flag antibody. (E) Recombinant GST-ER $\alpha-36$ was incubated with IKKe immunoprecipi-

A

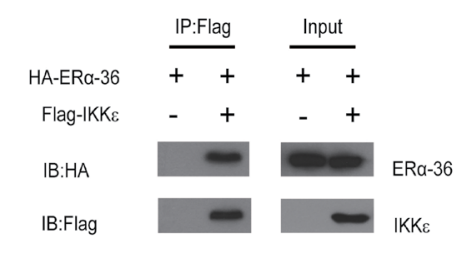

C

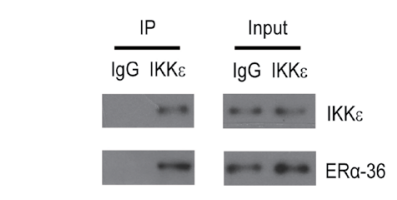

$E$

GST-ERa-36 + +

$$
\begin{aligned}
& \text { Flag-IKKE - + } \\
& \text { ERa-36 } \\
& \text { IB:GST } \rightleftharpoons \text { ERa-36 } \\
& \text { IB:Flag } \longrightarrow \text { IKK } \varepsilon
\end{aligned}
$$
tates from transfected 293T cells in the presence of $\left[\gamma^{-32} \mathrm{P}\right]-\mathrm{ATP}$. The reaction products were analyzed by SDS-PAGE and autoradiography.

ted with IKKe immunoprecipitates from transfected cells in the presence of [ $\gamma$-32P]-ATP. Analysis of the reaction products by SDS-PAGE and autoradiography showed that incubation of IKK $\varepsilon$ with GST-ER $\alpha-36$ resulted in phosphorylation of ER $\alpha-36$. These findings indicate that IKK $\varepsilon$ can phosphorylates ER $\alpha-36$ (Fig. 1E).

IKKE increase the expression of the ER $\alpha$-36 protein

To explore the possible effects of IKK $\varepsilon$ on ER $\alpha$-36, we first examined whether IKK $\varepsilon$ affects ER $\alpha-36$ expression. HEK-293T cells were cotransfected with Flag-tagged IKK $\varepsilon$ and HA-ER $\alpha-36$. The protein levels of ER $\alpha$ were greatly increased by WT IKKe. In contrast, kinase dead mutant of IKK $\varepsilon$ (K38A) resulted in a complete abolished IKKE-mediated ER $\alpha-36$ upregulation (Fig. 2A). Furthermore, overexpression of IKKe in ER $\alpha$-negtive breast cancer cell lines (MDA-MB-231 and MDA-MB-436) leads to increase the endogenous protein levels of ER $\alpha$-36. Similarly, overexpression of IKK $(\mathrm{K} 38 \mathrm{~A})$ mutation abolished IKKE-mediated endogenous ER $\alpha-36$ upregulation in these cell lines (Fig. 2B). In addition, decreasing the endogenous amount of IKKe in human MDAMB-231 and MDA-MB-436 cells with IKKe siRNA oligos led to decrease the endogenous protein levels of ER $\alpha-36$, and this phenotype was reversed by cotransfected with IKK $\varepsilon$ (res) plasmid and IKK $\varepsilon$ siRNA oligos (Fig. 2C). Therefore, we suggest that IKK $\varepsilon$-mediated increase of ER $\alpha-36$ protein expression, and this effect probably mediated by IKKe kinase activitys. Moreover, deletion of the kinase domain of IKK $\varepsilon$ abolishes the IKK $\varepsilon$-induced increase the expression of ER $\alpha$-36 (Fig. 2D). In order to explore whether IKKe regulates ER $\alpha-36$ at transcriptional level, Realtime-PCR analysis was done. Realtime-PCR analysis showed no significant difference in the transcriptional level of $\mathrm{ER} \alpha-36$ by IKK $\varepsilon$ overexpression (Fig. 2E).

IKKE enhance ER $\alpha-36$ mediated mitogenic estrogen signaling in ER-negative breast cancer cells

Previous reports have indicated that ER $\alpha$-36 mediates mitogenic estrogen signaling in ERnegative breast cancer cells. $E_{2} \beta$ stimulates a rapid activation of the MAPK/ERK pathway mediated by $E R \alpha-36$. Consequently, $E_{2} \beta$ was also able to induce expression of the growth-promoting genes c-Myc and cyclin D1. We then decided to determine whether IKKe impact the estrogen- 
Fig. 2. IKKe increase the expression of the ER $\alpha-36$ protein. (A) HEK-293T cells were cotransfected with HA-tagged ER $\alpha-36$ and Flag-tagged IKK $\varepsilon$ or IKKe kinase dead mutant (K38A), Whole-cell lysates were analyzed by immunoblotting with anti-Flag or anti-HA antibody, $\beta$-actin was used as equal loading control. Columns represent the means of three experiments; bars represent the s.e. ${ }^{*} \mathrm{P}<0.05$. (B) MDA-MB-231 and MDAMB-436 cells were transiently transfected with Flag-tagged IKK $\varepsilon$ or IKKe kinase dead mutant (K38A), Whole-cell lysates were analyzed by immunoblotting with anti-IKKe or anti-ER $\alpha-36$ antibody. Columns represent the means of three experiments; bars represent the s.e. ${ }^{*} \mathrm{P}<0.05$. (C) MDA-MB-231 and MDAMB-436 cells transfected with silKKe and a siRNA-resistant IKK $\varepsilon$ (IKK $\varepsilon$-res) expression plasmid. Whole-cell lysates were analyzed by immunoblotting with anti-IKKe or anti-ER $\alpha-36$ antibody, $\beta$-actin was used as equal loading control. Columns represent the means of three experiments; bars represent the s.e. ${ }^{*} \mathrm{P}<0.05$. (D) MDA-MB-231 cells were co-transfected with the indicated plasmids, Whole-cell lysates were analyzed by immunoblotting with anti-Flag or antiER $\alpha$-36 antibody, $\beta$-actin was used as equal loading control. (E) MDA-MB-231 cells transfected with vector or IKKe expression plasmids. RNA was extracted $24 \mathrm{hr}$ later, ER $\alpha-36 \mathrm{mRNA}$ level was analyzed by quantitative realtime-PCR.

activated MAPK pathway mediated by ER $\alpha-36$, we use a luciferase reporter construct containing the ERK-responsive transactivation domain of human Elk, which is a downstream effector of the MAPK/ERK signaling pathway. The HEK-293T cells were transfected with ERK-responsive GALElk chimeric transcription factor and GAL4 fused ERK-responsive transactivation domain of Elk1. The activity of a luciferase reporter gene containing GAL4-binding sites in the presence of $E_{2} \beta$ was measured. $E_{2} \beta$ treatment of IKKe and ER $\alpha-36$ cotransfected cells induced increase of Elk/ Gal4 fusion protein-mediated transactivation of the reporter gene than transfected with ER $\alpha-36$ alone, whereas no effect on the transcription activity of the Elk/Gal4 fusion protein in the control cells transfected with empty vector or $\mathrm{E}_{2} \beta$ absence cells (Fig. 3A). Furthermore, IKKe transfected cells also increase transcription activity of the Elk/Gal4 than transfected with empty vector in ER-negative breast cancer cells (MDA-MB-231 and MDA-MB-436), whereas no effect on the transcription activity of the Elk/Gal4 in the cells transfected with siRNA oligos or $\mathrm{E}_{2} \beta$ absence cells (Fig. 3B and C). Consequently, IKKe was also able to enhance expression of the growth-pro- 


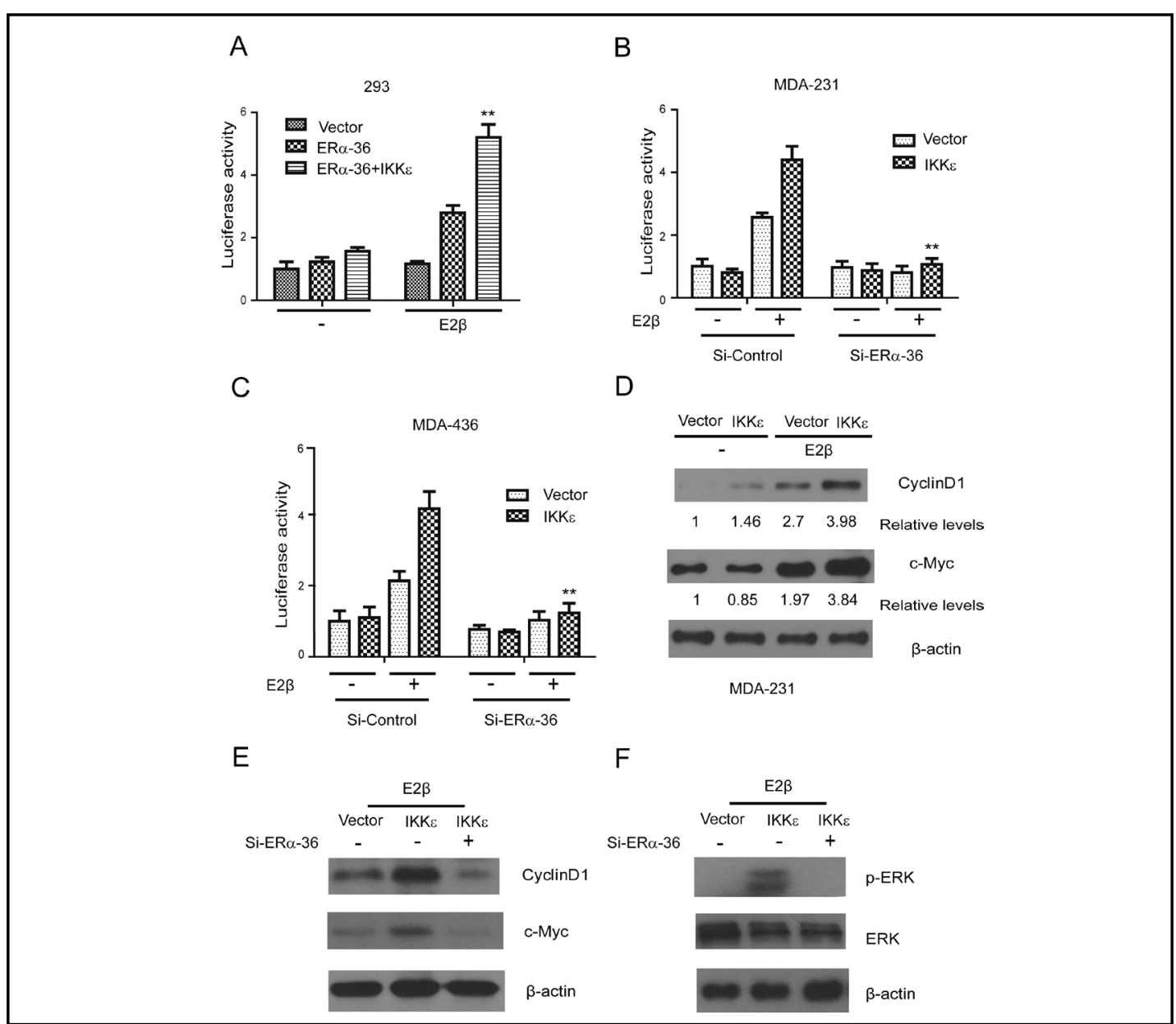

Fig. 3. IKKe enhance ER $\alpha-36$ mediated mitogenic estrogen signaling. (A) HEK-293T cells were cotransfected with Flag-IKKe, HA-ER $\alpha-36$, Gal4-LUC luciferase reporter plasmid and the Gal-ELK expression vector. The cell cultures were maintained in estrogen-free medium for $36 \mathrm{~h}$ before $\mathrm{E}_{2} \beta$ (10 nM) was added for $12 \mathrm{~h}$. Luciferase activities with SDs representative of more than three experiments performed in duplicate. MDA-MB-231 (B) and MDA-MB-436 (C) cells were cotransfected with Flag-IKKe, siER $\alpha-36$ oligo, Gal4-LUC luciferase reporter plasmid and the Gal-ELK expression vector. The cell cultures were maintained in estrogenfree medium for $36 \mathrm{~h}$ before $\mathrm{E}_{2} \beta(10 \mathrm{nM})$ was added for $12 \mathrm{~h}$. Luciferase activities with SDs representative of more than three experiments performed in duplicate. (D) MDA-MB-231 cells transfected with Flag-IKKe. The cell cultures were maintained in estrogen-free medium for $36 \mathrm{~h}$ before $E_{2} \beta(10 \mathrm{nM})$ was added for 12 $\mathrm{h}$. Whole-cell lysates were analyzed by immunoblotting with anti-c-Myc or anti-CyclinD1 antibody, $\beta$-actin was used as equal loading control. (E) MDA-MB-231 cells transfected with indicated plasmids or siER $\alpha-36$ oligo. The cell cultures were maintained in estrogen-free medium for $36 \mathrm{~h}$ before $\mathrm{E}_{2} \beta(10 \mathrm{nM})$ was added for $12 \mathrm{~h}$. Whole-cell lysates were analyzed by immunoblotting with anti-c-Myc or anti-CyclinD1 antibody, $\beta$-actin was used as equal loading control. (F) MDA-MB-231 cells transfected with indicated plasmids or siER $\alpha-36$ oligo. The cell cultures were maintained in estrogen-free medium for $36 \mathrm{~h}$ before $\mathrm{E}_{2} \beta(10 \mathrm{nM})$ was added for $12 \mathrm{~h}$. Whole-cell lysates were analyzed by immunoblotting with anti-p-ERK or anti-ERK antibody, $\beta$-actin was used as equal loading control.

moting genes c-Myc and cyclin D1 in MDA-MB-231 cell lines with E2 $\beta$ treated (Fig. 3D). We also found that IKKe failed to enhance expression of c-Myc and cyclin D1 in MDA-MB-231 cell lines

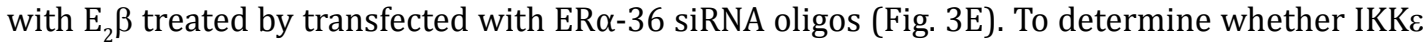
induced phosphorylation of the MAPK/ERK1/2 mediated by ER $\alpha-36$, we transfected cells with IKK $\varepsilon$ and ER $\alpha-36$ siRNA oligos to decrease the endogenous protein levels of ER $\alpha-36$. The signal 
Fig. 4. IKKe promote ER-negative breast cancer cell growth mediated by ER $\alpha-36$. (A, B) MDA-MB-231 and MDA-MB-436 cells were transfected with $\mathrm{IKK} \varepsilon$ were seeded at a density of $1 \times 10^{4}$ per well in six-well plates. The cell cultures were maintained in estrogen-free medium for $36 \mathrm{~h}$ before E2 $\beta$ (10 nM) was added for $12 \mathrm{~h}$. Cell viability was assessed at the indicated times. Bars represent the s.e. ${ }^{*} \mathrm{P}<0.05$. (C) MDA-MB-231 transfected with IKK $\varepsilon$ or cotransfected with IKK $\varepsilon$ and ER $\alpha-36$ siRNA were seeded at a density of $1 \times 10^{4}$ per well in six-well plates. The cell cultures were maintained in estrogen-free medium for $36 \mathrm{~h}$ before $\mathrm{E} 2 \beta(10 \mathrm{nM})$ was added for $12 \mathrm{~h}$. Cell viability was assessed at the indicated times. Bars represent the s.e. ${ }^{*} \mathrm{P}<0.05$.

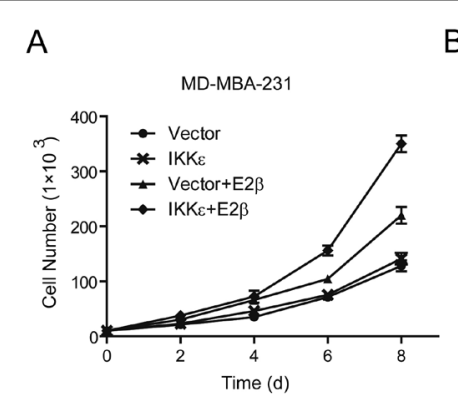

C

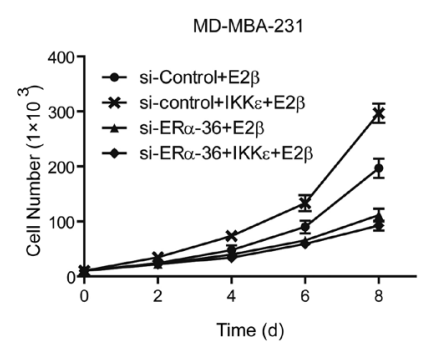

B

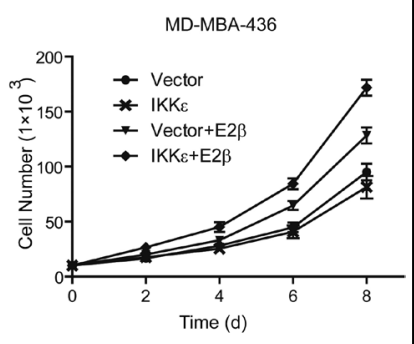

D

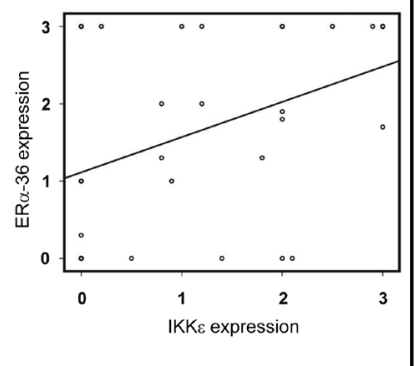

(D) Scatter plot of IKKe and ER $\alpha$-36 expression in ER $\alpha$-negative breast cancer from 25 patients. IKKe shows positively correlated with ER $\alpha-36$ in breast cancer samples using Spearman's correlation analysis $(\mathrm{P}=0.036, \mathrm{r}=0.384)$.

for p-ERK was significantly enhanced by overexpressed IKKe, whereas this increased phosphorylation was greatly reduced by ER $\alpha-36$ siRNA oligos(Fig. $3 F$ ). These results demonstrated that IKK $\varepsilon$ enhance ER- $\alpha 36$ mediated mitogenic estrogen signaling.

IKKE promote ER-negative breast cancer cell growth mediated by ER $\alpha-36$

To further pursue the significance of IKK $\varepsilon$-ER $\alpha-36$ interaction, we tested whether IKK $\varepsilon$ impact ER $\alpha-36$ mediates estrogen-stimulated cell proliferation. In assays of anchorage-dependent growth, MDA-MB-231 cells and MDA-MB-436 cells transfected with IKKe grew faster than those transfected with empty vector with $E_{2} \beta$ treated, whereas IKKe had no effect on the growth of the control MDA-MB-231 cells without $E_{2} \beta$ treated (Fig. 4A and B). ER $\alpha-36$ knockdown almost completely abolished IKKe-mediated growth stimulation of MDA-MB-231 cells (Fig. 4C). In order to further support the role of IKKe in ER $\alpha$-negative breast cancer as well as to substantiate the functional link between IKKe and ER $\alpha-36$ and extend the physiological relevance of this link, we collected 25 ER $\alpha$-negative breast cancer samples from breast cancer patients. The expression of IKK $\varepsilon$ and ER $\alpha-36$ was analyzed by immunohistochemistry staining with an antibody of IKKe and ER $\alpha-36$. The results suggested that IKKe had a significant positive correlation with ER $\alpha-36$ expression ( $\mathrm{P}=0.036, \mathrm{r}=0.384$ ) (Fig. $4 \mathrm{D}$ ).

\section{Discussion}

Breast cancer is the most common malignant tumor which is the leading cause of cancer-related deaths in women worldwide [21]. ER- $\alpha$ expression is one of the most important responses to endocrine therapy [22]. Approximately $70 \%$ of breast cancer cases are ER $\alpha$-positive, and the remaining 30\% are ER-negative [10]. ER $\alpha-36$ is a variant of conventional ER $\alpha$, which lacks both transcriptional activation domains of $E R \alpha-66$, retains DNA-binding domain, partial dimerization and ligand-binding domains, and possesses a unique 27 amino acid domain that replaces the last 138 amino acid of ER $\alpha-66[11,13]$. It was found that ER $\alpha-36$ expression levels were higher in ERnegative tumors and lower in ER-positive tumors [12]. ER- $\alpha 36$ mediated mitogenic estrogen signaling in ER-negative breast cancer cells, such as MDA-MB-231 and MDA-MB-436 cells that lack 
expression of ER- $\alpha 66$ but highly express ER- $\alpha 36$. It was reported that $\mathrm{E}_{2} \beta$ induced the MAPK/ ERK activation through a mechanism that involves ER- $\alpha 36$ and the EGFR/Src/Shc complex and exhibited a potent mitogenic estrogen signaling in vitro and in vivo [11,12,14].

In the present study, we identified that IKKe interacts with ER $\alpha-36$, increases the expression of ER $\alpha-36$ in MDA-MB-231 and MDA-MB-436 breast cancer cells. Additionally, IKKe enhances ER $\alpha-36$ mediated mitogenic estrogen signaling and promotes ER-negative breast cancer cell growth mediated by ER $\alpha-36$.

IKKe is a member of IKK family, and shares $30 \%$ amino acid identity with IKK $\alpha$ and IKK $\beta$ in their kinase domains [15]. IKKe plays a central role in regulating innate immunity by activating the NF- $\mathrm{KB}$ signaling pathway and phosphorylating IRF3 and IRF7 to regulate the type I interferon response [16]. IKKe also phosphorylates the tumor suppressor CYLD and promotes cell transformation [23]. In addition, recent study indicated that IKKe is amplified in a substantial percentage of human breast tumors and acts as an oncogene in breast cancers [19]. Especially, IKK $\varepsilon$ phosphorylates ER $\alpha$ on Ser-167 site, leading to activation of ER $\alpha$ and up-regulation of cyclin D1. Furthermore, overexpression of IKK $\varepsilon$ in ER $\alpha$-positive breast cancer cells induces tamoxifen resistance [20]. This effect mainly required kinase activity of IKKe. In this study, we found that kinase lethal mutant of IKK $\varepsilon(\mathrm{K} 38 \mathrm{~A})$ resulted in a complete abolished IKKe-mediated ER $\alpha-36$ upregulation, indicating that ER $\alpha-36$ may be a new IKKe kinase substrate.

In summary, we have shown that breast oncogene IKK $\varepsilon$ interacts with ER $\alpha-36$, and increases ER $\alpha$-36 expression in ER-negative breast cancer cells. In addition, IKK $\varepsilon$ increases ER $\alpha$-36 mediated MAPK/ERK signaling pathway, and enhances nongenomic estrogen signaling, contributing to development and progression of ER-negative breast cancer cells. Therefore, IKKe plays important roles in breast cancer tumorigenesis, and may be a very effective target for breast cancer therapy through regulating multiple signaling pathways.

\section{Conflict of Interest}

None.

\section{Acknowledgements}

This work is supported by Chinese National Natural Sciences Foundation (No. 81102673 and No. 61101218) and Beijing NOVA Program (Z121107002512078).

\section{References}

1 Landis SH, Murray T, Bolden S, Wingo PA: Cancer statistics, 1999. CA Cancer J Clin 1999;49:8-31, 31.

2 Osborne CK, Schiff R: Mechanisms of endocrine resistance in breast cancer. Annu Rev Med 2011;62:233-247.

3 Speirs V, Skliris GP, Burdall SE, Carder PJ: Distinct expression patterns of er alpha and er beta in normal human mammary gland. J Clin Pathol 2002;55:371-374.

4 Giuliano M, Schifp R, Osborne CK, Trivedi MV: Biological mechanisms and clinical implications of endocrine resistance in breast cancer. Breast 2011;20:S42-49.

5 Wang D, Huang P, Zhu B, Sun L, Huang Q Wang J: Induction of estrogen receptor alpha-36 expression by bone morphogenetic protein 2 in breast cancer cell lines. Mol Med Rep 2012;6:591-596.

6 Fowler AM, Santen RJ, Allred DC: "Dwarf" estrogen receptor in breast cancer and resistance to tamoxifen. J Clin Oncol 2009;27:3413-3415.

7 Masood S: Estrogen and progesterone receptors in cytology: A comprehensive review. Diagn Cytopathol 1992;8:475-491. 


\section{Cellular Physiology $\quad$ Cell Physiol Biochem 2013;31:833-841 and Biochemistry

8 McGuire WL, Chamness GC, Fuqua SA: Estrogen receptor variants in clinical breast cancer. Mol Endocrinol 1991;5:1571-1577.

-9 Johnston SR: New strategies in estrogen receptor-positive breast cancer. Clin Cancer Res 2010;16:1979-1987.

10 Chen JQ Russo J: Eralpha-negative and triple negative breast cancer: Molecular features and potential therapeutic approaches. Biochim Biophys Acta 2009;1796:162-175.

11 Wang Z, Zhang X, Shen P, Loggie BW, Chang Y, Deuel TF: A variant of estrogen receptor- $\alpha$, her- $\alpha 36$ : Transduction of estrogen- and antiestrogen-dependent membrane-initiated mitogenic signaling. Proc Nat Acad Sci USA 2006;103:9063-9068.

12 Zhang X, Ding L, Kang L, Wang ZY: Estrogen receptor-alpha 36 mediates mitogenic antiestrogen signaling in ernegative breast cancer cells. PloS One 2012;7:e30174.

13 Shi L, Dong B, Li Z, Lu Y, Ouyang T, Li J, Wang T, Fan Z, Fan T, Lin B, Wang Z, Xie Y: Expression of er- $\alpha 36$, a novel variant of estrogen receptor $\alpha$, and resistance to tamoxifen treatment in breast cancer. J Clin Oncol 2009;27:34233429.

14 Zhang XT, Kang LG, Ding L, Vranic S, Gatalica Z, Wang ZY: A positive feedback loop of er-alpha36/egfr promotes malignant growth of er-negative breast cancer cells. Oncogene 2011;30:770-780.

15 Clement JF, Meloche S, Servant MJ: The ikk-related kinases: From innate immunity to oncogenesis. Cell Res 2008;18:889-899.

16 Hacker H, Karin M: Regulation and function of ikk and ikk-related kinases. Sci STKE 2006;2006:re13.

17 Shen RR, Hahn WC: Emerging roles for the non-canonical ikks in cancer. Oncogene 2011;30:631-641.

18 Tenoever BR, Ng SL, Chua MA, McWhirter SM, Garcia-Sastre A, Maniatis T: Multiple functions of the ikk-related kinase ikkepsilon in interferon-mediated antiviral immunity. Science 2007;315:1274-1278.

19 Boehm JS, Zhao JJ, Yao J, Kim SY, Firestein R, Dunn IF, Sjostrom SK, Garraway LA, Weremowicz S, Richardson AL, Greulich H, Stewart CJ, Mulvey LA, Shen RR, Ambrogio L, Hirozane-Kishikawa T, Hill DE, Vidal M, Meyerson M, Grenier JK, Hinkle G, Root DE, Roberts TM, Lander ES, Polyak K, Hahn WC: Integrative genomic approaches identify ikbke as a breast cancer oncogene. Cell 2007;129:1065-1079.

20 Guo JP, Shu SK, Esposito NN, Coppola D, Koomen JM, Cheng JQ: Ikkepsilon phosphorylation of estrogen receptor alpha ser-167 and contribution to tamoxifen resistance in breast cancer. J Biol Chem 2010;285:3676-3684.

21 Parkin DM, Bray F, Ferlay J, Pisani P: Global cancer statistics, 2002. CA Cancer J Clin 2005;55:74-108.

22 Yamashita H, Yando Y, Nishio M, Zhang Z, Hamaguchi M, Mita K, Kobayashi S, Fujii Y, Iwase H: Immunohistochemical evaluation of hormone receptor status for predicting response to endocrine therapy in metastatic breast cancer. Breast Cancer 2006;13:74-83.

23 Hutti JE, Shen RR, Abbott DW, Zhou AY, Sprott KM, Asara JM, Hahn WC, Cantley LC: Phosphorylation of the tumor suppressor cyld by the breast cancer oncogene ikkepsilon promotes cell transformation. Mol Cell 2009;34:461472 . 